\title{
THE EFFECTS OF LASER SURFACE HARDENING ON MICROSTRUCTURAL CHARACTERISTICS AND WEAR RESISTANCE OF AISI H11 HOT WORK TOOL STEEL
}

\begin{abstract}
The present study deals with the effects of laser surface treatment on microstructure evolution and wear resistance of AISI H11 hot work tool steel in quenched and tempered condition. The most upper laser-affected zone is characterized by re-melted microstructure consisting of dendrite cells with fresh non-tempered martensite, retained austenite and inter-dendritic carbidic network. The subsolidus microstructure just beneath the re-melted zone represents the most laser surface hardened zone consisting of fresh non-tempered martensite with fine and coarse carbides as a result of overheating the original QT substrate microstructure. The highest microhardness values in the range from 775 to $857 \mathrm{HV}$ were measured for the LSH microstructure and the most softened microstructure exhibited the minimum hardness of $530 \mathrm{HV}$. The laser treated samples showed the improvement of their surface wear resistance by $35 \%$.
\end{abstract}

Keywords: Hot work tool steel, laser hardening, microstructure, hardness, wear resistance

\section{Introduction}

Nowadays several technologies of surface processing of metallic materials are employed to improve wear and corrosion resistance. These include physical methods such as flame hardening, induction hardening, electrolytic quenching, electro-spark hardening, and physical vapor deposition and also chemical methods such as carburizing, nitriding, chemical vapor deposition, diffusion treatment, and metallic cementation [1,2]. Surface treatment with laser radiation takes advantage of selfquenching effect that enables rapid cooling of the treated zone into bulk material without the need of any external quenching media. The details on phenomena of superficial hardening of the hot-work tool steels can be found in [3]. The major benefits of laser hardening consist in narrow heat-affected zone due to low input energy, smooth surface after the treatment and thus no need for any post-process surface machining [2]. In addition, microstructural features of the laser treated surfaces possess the increased strength, wear and corrosion resistance i.e. all the properties required for application of hot work tool steels used in high speed machining processes [4,5].

AISI $\mathrm{H} 11$ is a $5 \% \mathrm{Cr}$ hot work tool steel that contains $1.3 \%$ Mo, $0.40 \% \mathrm{~V}$, and $1.1 \% \mathrm{Si}$ as main alloying elements. It exhibits high hardenability, excellent toughness and wear resistance suitable for hot work applications such as pressure die casting tools, extrusion tools, forging dies etc. Currently, the literature information about laser surface hardening (LSH) of AISI H11 steel in its quenched and tempered (QT) condition is rather limited, compared to the more examined AISI H13 steel [6,7]. The AISI H11 and AISI H13 steels, used in the same applications, are characterized by mutually similar chemical compositions, basically differing only within their vanadium content.

It has been described in literature [8] that rapid cooling of AISI H13 steel from austenitizing temperature leads to both higher saturation of alloying elements in solid solution and the precipitation of fine carbides. This is basically the reason for its higher surface hardness resulting in longer life time of a tool. In the case of laser surface hardening applied to martensitic tool steel [9], fine carbides in the martensite notably improved its wear resistance, compared to the application of conventional QT heat treatment.

The LSH has usually been studied on tool steels in their as-received (AR) soft-annealed state in contrast to the QT state used within engineering practice. Therefore, the present study deals with the effect of LSH on microstructure evolution and wear resistance of AISI H11 tool steel in its initial QT state.

\section{Experimental procedure}

The hot work tool steel AISI H11 with the chemical composition shown in Table 1 was oil quenched after the austenitization at $1040^{\circ} \mathrm{C}$ for $20 \mathrm{~min}$ and subsequently tempered at $550^{\circ} \mathrm{C}$ for $2 \mathrm{~h}$ obtaining the hardness of 52 HRC.

\footnotetext{
* SLOVAK ACADEMY OF SCIENCES, INSTITUTE OF MATERIALS RESEARCH, KOŠICE, SLOVAK REPUBLIC

*** P.J. ŠAFÁRIK UNIVERSITY IN KOŠICE, DEPARTMENT OF CONDENSED MATTER PHYSICS, INSTITUTE OF PHYSICS, KOŠICE, SLOVAK REPUBLIC 
TABLE 1

Chemical composition of AISI H11 hot work tool steel in wt. \%

\begin{tabular}{|c|c|c|c|c|c|}
\hline \hline $\mathbf{C}$ & $\mathbf{S i}$ & $\mathbf{M n}$ & $\mathbf{C r}$ & $\mathbf{M o}$ & $\mathbf{V}$ \\
\hline 0.38 & 1.10 & 0.40 & 5.00 & 1.30 & 0.40 \\
\hline
\end{tabular}

The surface hardening of AISI H11 tool steel in its initial QT condition was carried out using fibre laser TruFiber 400 with a scanning optical head. The dimensions of the AISI H11 steel specimen and the used LSH parameters are depicted in Fig. 1.

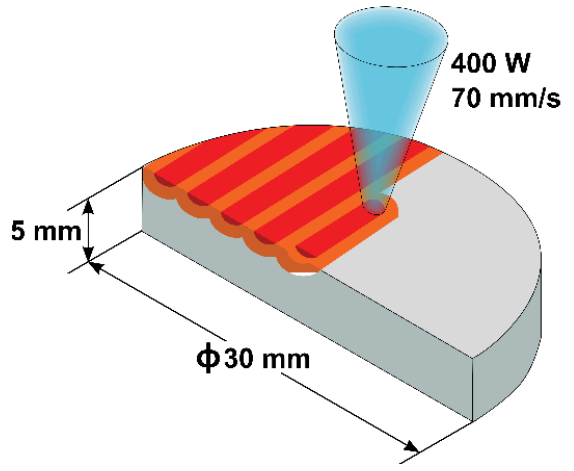

\section{Power \\ [W] \\ Scan rate $[\mathrm{mm} / \mathrm{s}]$ \\ Spot size [mm] \\ Fill spacing \\ [mm]}

400

Fig. 1. Sample dimensions and used LSH parameters

The microstructure analyses were carried out in a direction of the sample thickness using scanning electron microscope (SEM) JEOL JSM 7000F with energy dispersive X-ray (EDX) analyzer. The substructures of thin foils in QT and LSH states were characterized by transmission electron microscope (TEM) JEOL $2100 \mathrm{~F}$ using bright field image mode. The prepared discs were electrolytically polished in a solution of $\mathrm{CH}_{3} \mathrm{OH}$ and $\mathrm{HClO}_{4}$ at the ratio of 9:1 per volume, using a standard double-jet procedure. The polishing process was performed in the temperature range from $-25^{\circ} \mathrm{C}$ to $-15^{\circ} \mathrm{C}$ at polishing voltage of $18 \mathrm{~V}$.

The microhardness measurements were conducted using Vickers microhardness tester LECO LM700 at applied load of $50 \mathrm{~g}$. The microhardness profiles were performed in the thickness direction of the sample, i.e. from the top surface of the sample to the base (substrate) material and in the direction perpendicular to laser beam tracks (i.e. parallel to the sample surface line) in the depth lines of $0.07 \mathrm{~mm}$ and $0.18 \mathrm{~mm}$, respectively. With respect to the perpendicular direction, the microhardness was measured along the length of approximately $2 \mathrm{~mm}$ between two neighboring tracks from the centre of one laser beam track to the other.

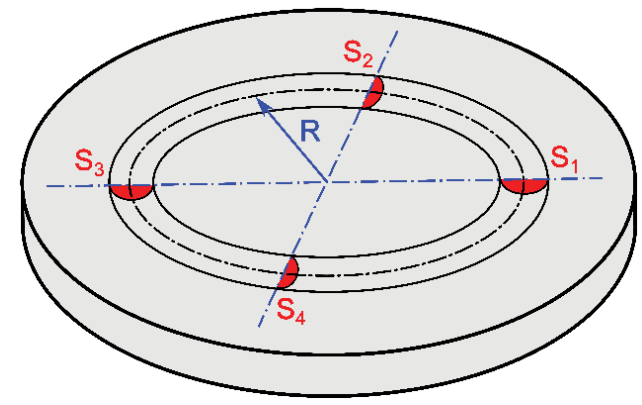

Fig. 2. Wear track on disc specimen
The wear resistance of the LSH zone was evaluated at room temperature by the "ball-on-disc" method (ISO20808) using a stationary $\mathrm{Al}_{2} \mathrm{O}_{3}$ ball with $8 \mathrm{~mm}$ diameter, under a load of $5 \mathrm{~N}$, at a speed of $0.1 \mathrm{~m} / \mathrm{s}$, with wear track radius and distance of $3 \mathrm{~mm}$ and $1000 \mathrm{~m}$, respectively (Fig. 2). The size and morphology of the wear track was characterized using confocal microscope Sensofar PLu Neox.

\section{Results and discussion}

\subsection{Microstructural analyses}

Figure 3 shows a cross-sectional general view on the laseraffected microstructure of studied AISI H11 tool steel with its four local sub-zones (Fig. 3a), microstructural details of the individual sub-zones (Fig. 3b-e), and the microstructure of base QT material unaffected by the used LSH process (Fig. 3f).

The most upper laser-affected zone i.e. the zone 1 (Fig. 3b) is characterized by re-melted dendritic microstructure consisting of dendrite cells with fresh non-tempered martensite, retained austenite and inter-dendritic carbidic network. Occasionally, some original undissolved fine carbides are also present in this zone. This observation agrees well with findings of other authors [10-12] revealed in similar AISI H13 tool steel. The subsolidus microstructure just beneath the re-melted zone i.e. the zone 2 (Fig. 3c) consists of fresh non-tempered martensite with original (undissolved) fine and coarsened carbides as a result of overheating of the original QT base material (substrate) microstructure. In contrast, the zone 3 (Fig. 3d) heated up to the normalization temperature range above $\mathrm{Ac}_{3}$ transformation temperature exhibits still non-tempered martensite with fine undissolved carbides originating from the initial QT microstructure. The occurrence of fine dispersed carbides in this zone is related to its lower austenitization temperature, compared to the previous zone. Fig. 3e shows the microstructure of the over-tempered zone 4 heated up to the temperatures around $\mathrm{Ac}_{1}$ transformation temperature. This zone is characterized by the highest degree of tempering of the original QT martensitic microstructure. The microstructure of the original QT base material (Fig. 3f) is formed of tempered martensite with homogeneously distributed fine carbides which agrees well with findings of other studies on hot work tool steels [13-15].

The comparison of individual substructures of AISI H11 tool steel in the initial QT condition and performed LSH treatment is shown in Fig. 4. The substructure of QT base material is typically formed of tempered martensite with fine carbides (Fig. 4a), whereas the LSH state is characterized by the presence of non-tempered (newly formed) fresh martensite.

In addition, it can be seen that the application of LSH treatment caused substantial refinement of martensite laths (Fig. 4a), compared to the substructure of the original base material in QT state (Fig. 4b). This observation qualitatively agrees with findings by Gao et al. [16] who studied martensite transformation in high $\mathrm{Cr}$ heat-resistant steel during continuous cooling and 

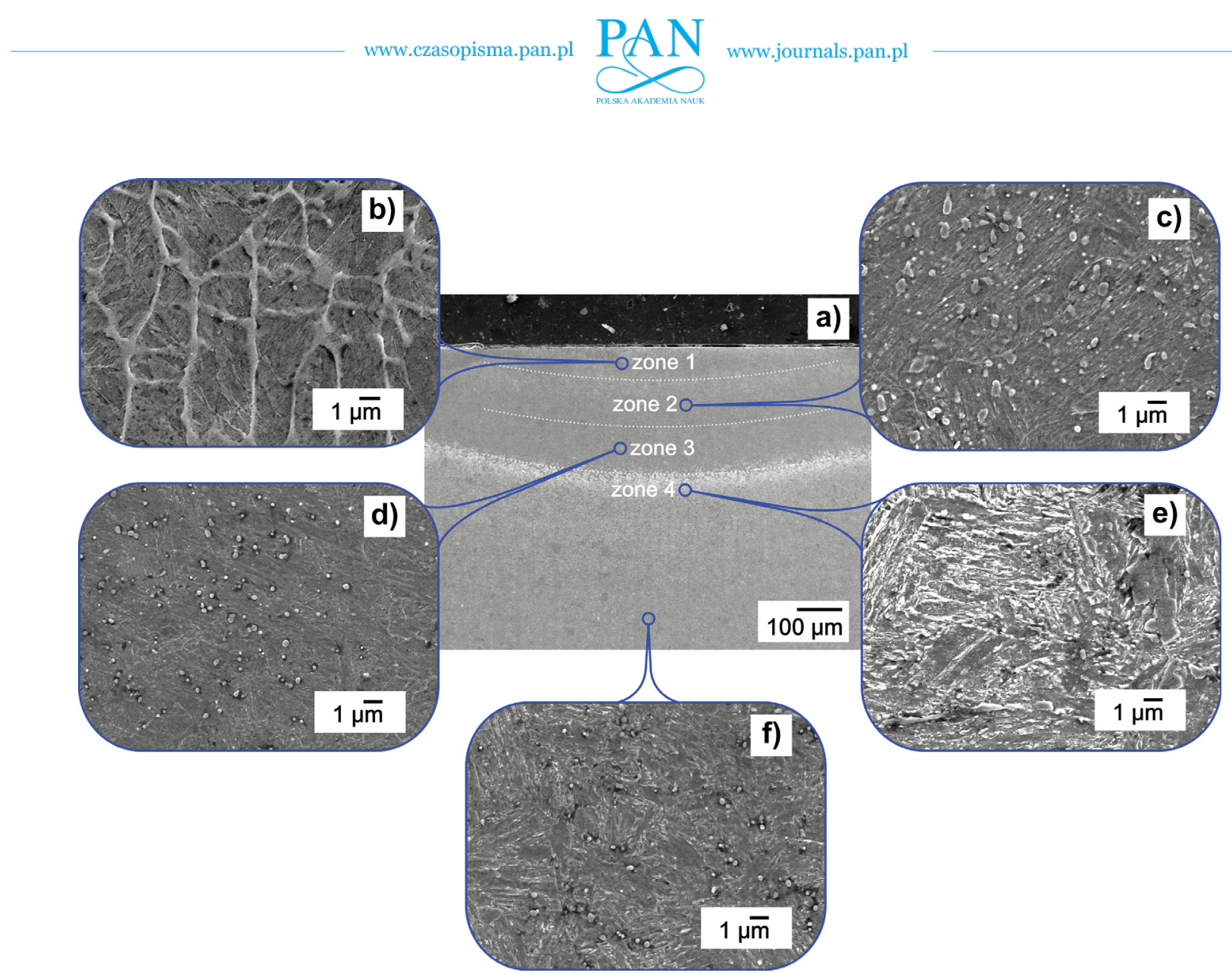

Fig. 3. SEM microstructures of AISI H11 tool steel: (a) general view on whole LSH microstructure with its four sub-zones; (b) zone 1; (c) zone 2; (d) zone 3; (e) zone 4; (f) original QT base material unaffected by laser treatment
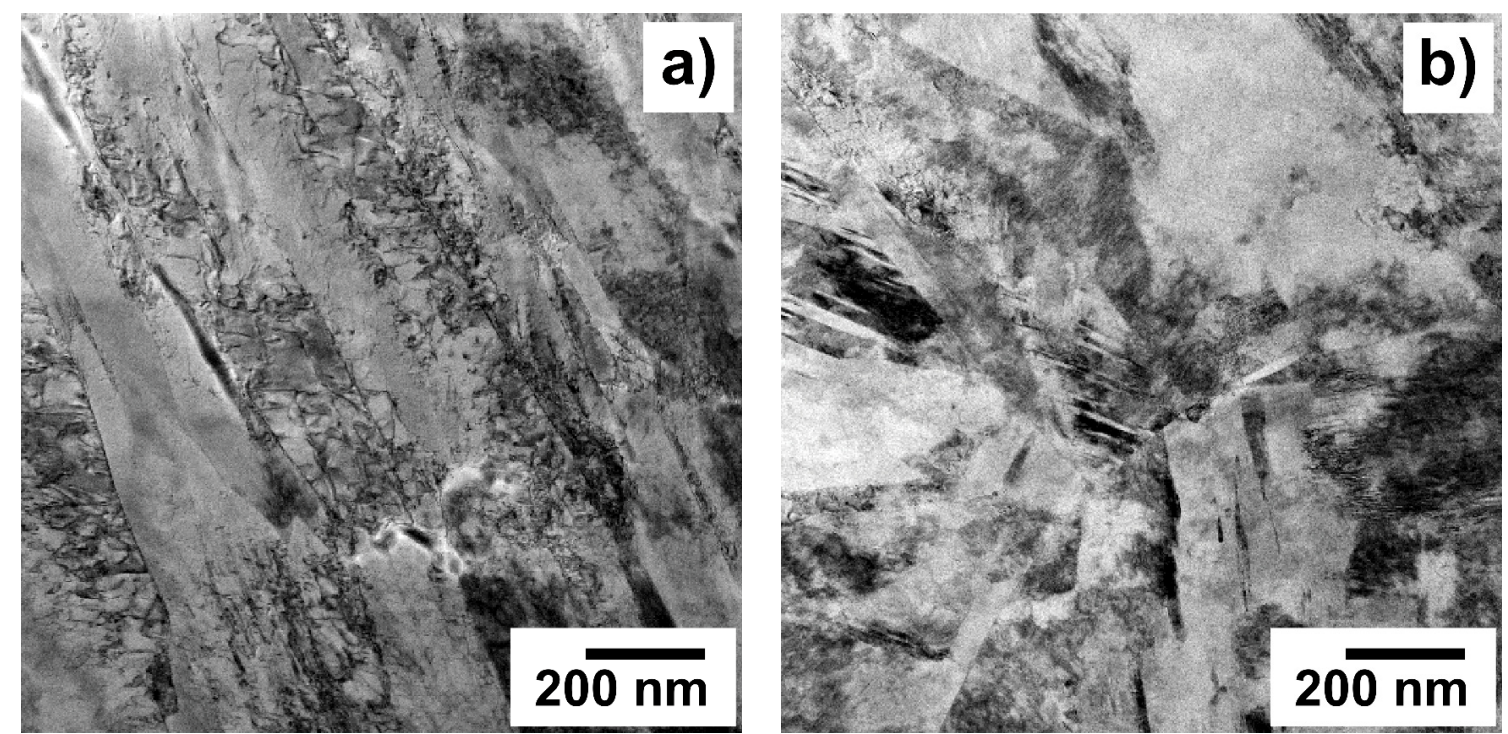

Fig. 4. Substructural characteristics of the studied AISI H11 hot work tool steel: a) QT base material, b) LSH zone 2 according to Fig. 3

revealed that with increasing cooling rate the aspect ratio of martensite laths decreases and their density increases.

\subsection{Microhardness measurements}

The microhardness profiles in the thickness direction and in a direction perpendicular to the laser beam tracks are shown in Fig. 5.
The profile in Fig. 5a exhibits a steep microhardness gradient which starts at the value of $820 \mathrm{HV}$ corresponding to the re-melted zone 1 with dendritic microstructure. The maximal hardness of $857 \mathrm{HV}$ is related to the fresh (newly-formed) non-tempered martensite microstructure of the zone 2 with the occurrence of fine and coarse carbides. The following gradual decreasing of hardness within the zone 3 was caused by the successive decreasing level of transformation (martensite) and precipitation (carbide) strengthening effects within the 

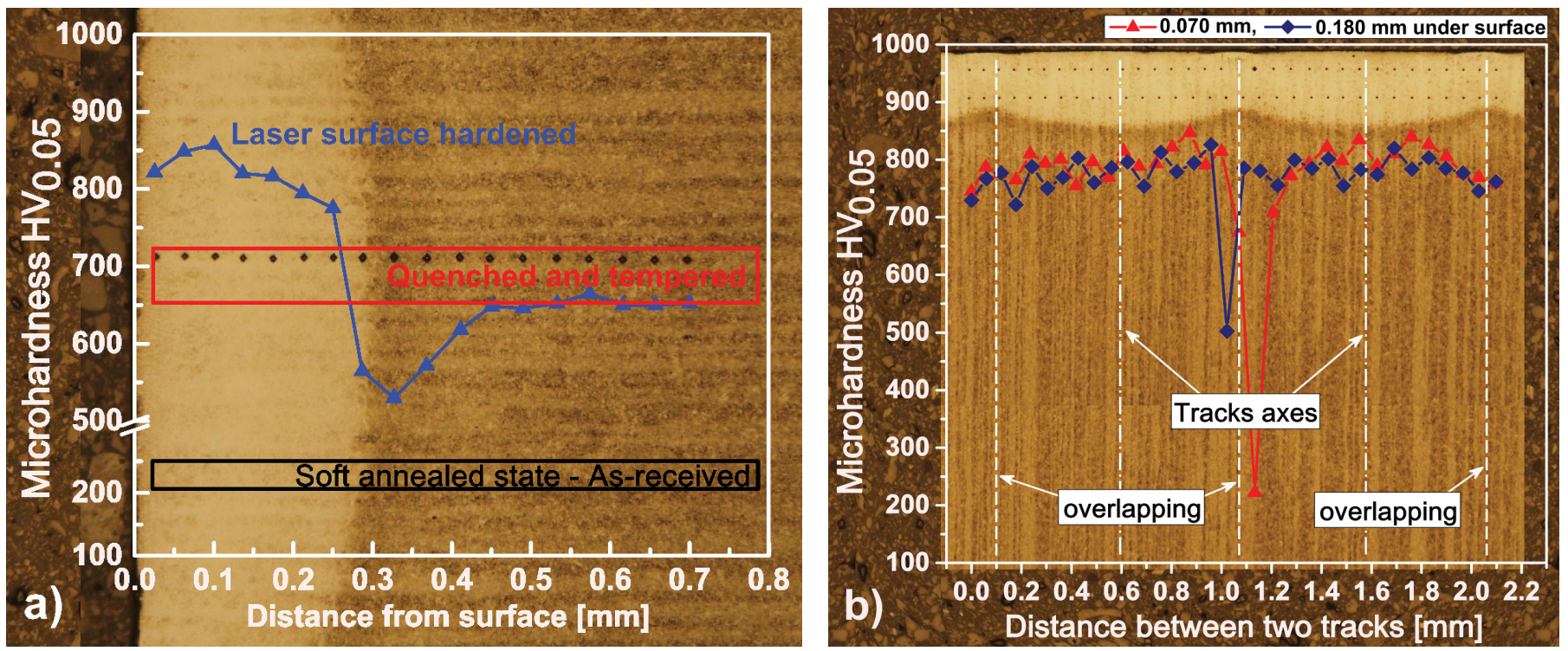

Fig. 5. Microhardness profile (a) in the thickness direction of LSH treated AISI H11 sample; (b) in the direction perpendicular to laser beam tracks i.e. between two neighboring track

normalization temperature range. The minimal hardness value of $530 \mathrm{HV}$ was detected in the most softened (over-tempered) microstructure of the zone 4 due to its highest level of tempering resulted from the local heating around the $\mathrm{Ac}_{1}$ transformation temperature. The final constant tendency of hardness profile values to be around $640-650 \mathrm{HV}$ is related to the original QT microstructure of AISI H11 base material unaffected by the used LSH treatment. It can be stated that the observed hardness profile gradient reflects the typical general shape of hardness profiles observed in fusion weldments of ferritic steels involving the welds of ferritic structural steels and those of normalized and tempered martensitic steels for high temperature applications [17]. Moreover, Kasman and Saklakoglu [18] also observed similar hardness gradient of laser engraved AISI H13 tool steel investigated in their study on the effect of process parameters on the steel surface characteristics.

Horizontal hardness profiles beneath two neighboring laser beam tracks (Fig. 5b) vary within the range of 710-820 HV for both measurement depths $(0.07 \mathrm{~mm}, 0.18 \mathrm{~mm})$. However, due to the local tempering effect as a consequence of partial overlapping of laser beam tracks [19], the pronounced local softening is observed resulting in microhardness values of $222 \mathrm{HV}$ and $502 \mathrm{HV}$ for the profiles in the depths of $0.07 \mathrm{~mm}$ and $0.18 \mathrm{~mm}$, respectively.

\subsection{Wear resistance}

Figure 6 shows the comparison of wear track profiles of AISI H11 steel base material in the as-received (AR) soft-annealed condition (Fig. 6a), quenched and tempered (QT) state (Fig. 6b) and after laser surface hardening (LSH) treatment (Fig. 6c). The laser-hardened surface exhibits the minimum penetration depth of $12.2 \mu \mathrm{m}$ at maximum roughness. This maximum roughness may be caused due to the overlapping and/or due to the ball to pull off surface material chips which are consequently pushed by the ball along the wear track. Figure 7 depicts the comparison of specific wear rate related to the individual materials states (AR, QT, LSH) showing the minimal value for LSH condition as also presented in [15]. This behavior of the laser-hardened surface can likely be related to the refinement of martensitic microstructure which also correlates well with the decrease of the friction coefficient [20]. The lowering of specific wear rate in the LSH condition of studied AISI H11 steel compared to the QT material state resulted in the increase of surface wear resistance by $35 \%$.

\section{Summary and conclusions}

Present investigation was focused on the effects of laser surface hardening of AISI H11 hot work tool steel in its initial quenched and tempered condition. For comparison, as-received soft-annealed material has also been analyzed. The obtained results can be summarized in the following conclusions:

- Temperature gradient caused by laser surface hardening treatment resulted in complex microstructural changes in quenched and tempered base material beneath applied laser beam tracks. The obtained microstructural variety included four typical zones, namely the re-melted dendritic microstructure with presence of fresh martensite and interdendritic carbides, the over-heated region with fresh martensite and coarsened carbides, normalized martensitic microstructure with fine carbides, and over-tempered martensitic region representing the locally softened zone.

- In accordance with the observed microstructural changes, the microhardness profile in the direction of the thickness the laser surface hardened sample shows a steep hardness gradient showing a variation of hardness values from the range of $775-857 \mathrm{HV}$ on the top surface of the sample to the final constant course in the range of 720-655 HV related to 


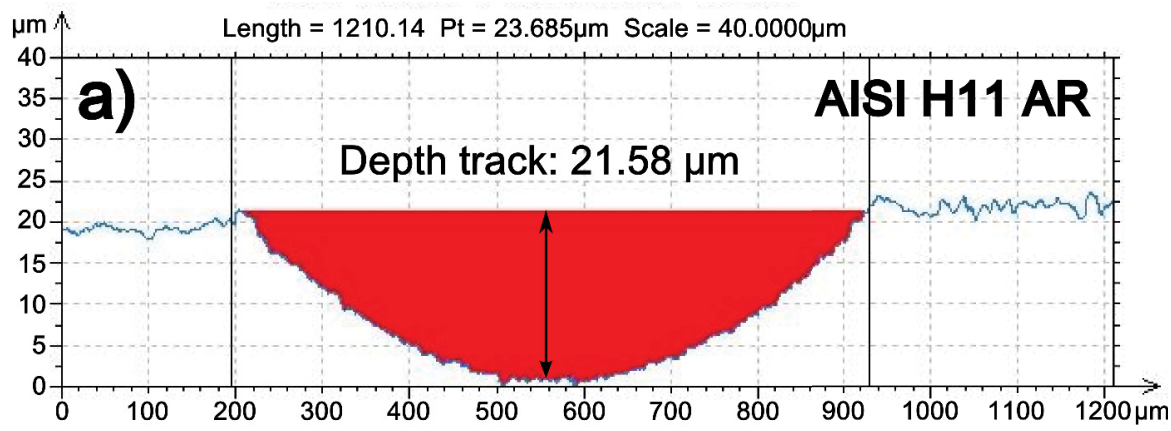

Maximum depth $21.5838 \mu \mathrm{m}$ Area of the hole $10160.1 \mu \mathrm{m}^{2}$

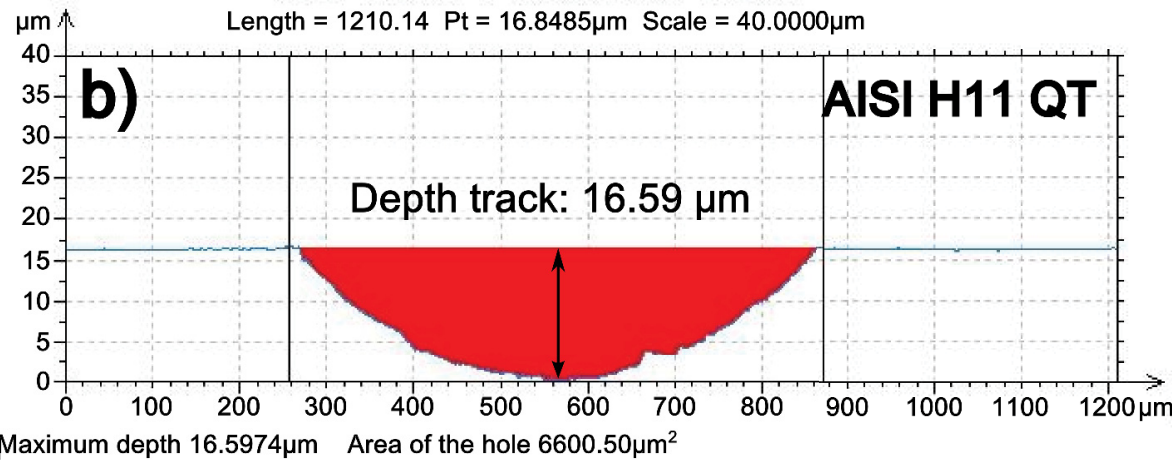

Maximum depth $16.5974 \mu \mathrm{m}$ Area of the hole $6600.50 \mu \mathrm{m}^{2}$

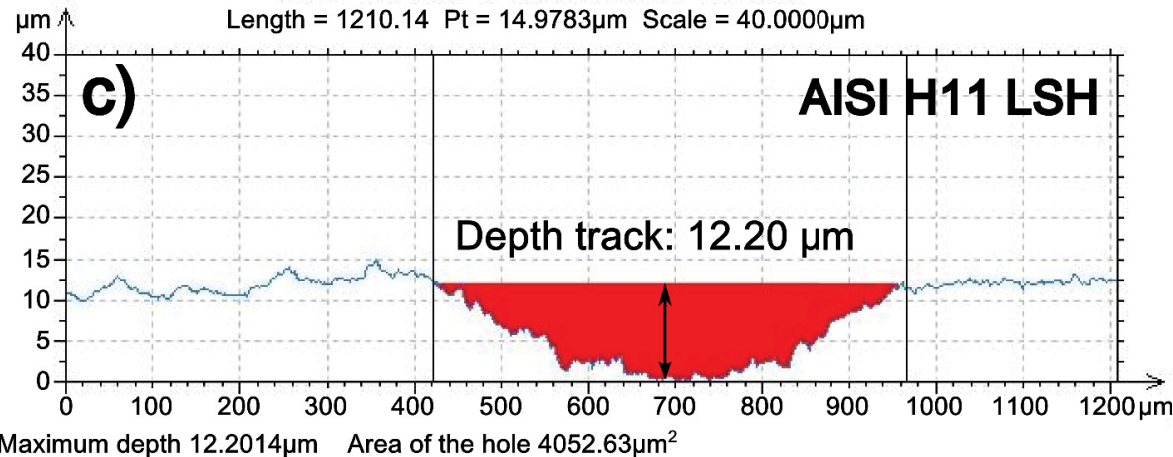

Fig. 6. Cross-section of the wear track for AISI H11 steel: (a) As-received soft-annealed state; (b) quenched and tempered base material and (c) laser surface hardened condition

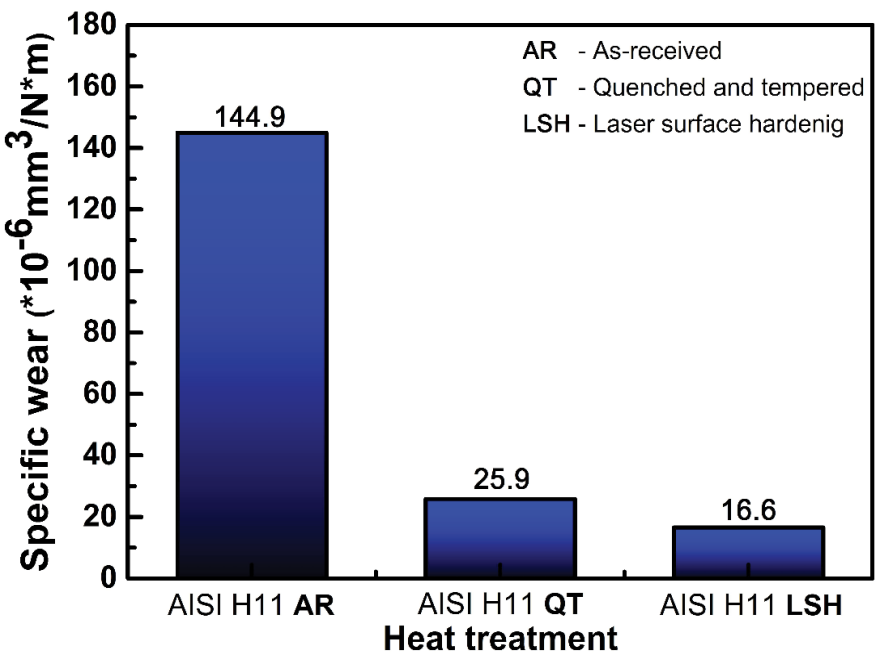

Fig. 7. Specific wear rate of individual material states of AISI H11 tool steel quenched and tempered base material. The minimum hardness value of $530 \mathrm{HV}$ was measured within over-tempered zone. The microhardness measurements in perpendicular direction to laser beam tracks also show local softening due to overlapping of neighboring laser tracks.

- Comparison of wear track profiles of AISI H11 tool steel in individual material states showed for the laser surface hardened condition the minimal penetration depth at maximum roughness. In addition, the specific wear rate decrease in laser surface hardened state showed the increase of surface wear resistance by $35 \%$, compared to the initial quenched and tempered condition.

\section{Acknowledgements}

This work was financially supported by the projects VEGA 2/0120/15, VEGA 2/0081/16, ITMS 26220220037, ITMS 26220220061 and ITMS 26220220064 . 


\section{REFERENCES}

[1] S.D. Choi, S.H. Cheong, S.C. Yang, J.G. Kim, SKD11 surface heat treatment characteristics by high power diode laser, Proceeding of KSMTE 2007 Autumn Annual Meeting, 380-385 (2007).

[2] J. Lee, J.H. Jang., B.D. Joo, Y.M. Son, Y.H. Moon, Transactions of Nonferrous Metals Society of China 19, 917-920 (2009).

[3] A. Bokota, A. Kulawik, R. Szymczyk, J. Wróbel, Archives of Metallurgy and Materials 60, 2763-2772 (2015).

[4] Y. van Ingelgem, I. Vandendael, D. van den Broek, A. Hubin, J. Vereecken, Electrochimica Acta 52, 7796-7801 (2007).

[5] H.B. Lee, I.S. Jang, D.H. Jung, K.S. Kim, Surface hardening of hot forging die using diode laser, Proceeding of Korea Society of Laser Processing 2002 Autumn Annual Meeting, 45-49, 2002.

[6] J. Dutta Majumdar, A.K. Nath, I. Manna, Surface \& Coatings Technology 204, 1326-1329 (2010).

[7] S.M. Shariff, T.K. Pal, G. Padmanabham, S.V. Joshi, Surface \& Coatings Technology 228, 14-26 (2013).

[8] J.W. Wallace, D. Schwam, Die Casting Engineer, May/June, 50-58 (2000).
[9] R. Colaco, C. Pina, R. Vilar, Scripta Materialia 41, 715-721 (1999).

[10] K.A. Chiang, Y.-C. Chen, Material Letters 59, 1919-1923 (2005).

[11] H.J. Shin, Y.T Yoo, Journal of Materials Processing Technology 201, 342-347 (2008).

[12] G. Telasang, J. Dutta Majumdar, G. Padmanabham, I. Manna, Material Science Engineering A 599, 255-267 (2014).

[13] J.R.T. Branco, G. Krauss, Proceedings of the $6^{\text {th }}$ International Congress on Heat Treatment of Metals, Chicago, 195-198, 1988.

[14] A. Medvedeva, J. Bergstrom, S. Gunnarsson, J. Andersson, Material Science Engineering A 523, 29-46 (2009).

[15] G. Telasang, J. Dutta Majumdar, G. Padmanabham, I. Manna, Surface \& Coatings Technology 261, 69-78 (2015).

[16] Q. Gao, Y. Liu, X. Di, L. Yu, Z. Yan, J. Mater. Res. 27, 2779-2789 (2012).

[17] L. Falat, L. Čiripová, J. Kepič, J. Buršík, I. Podstranská, Engineering Failure Analysis 40, 141-152 (2014).

[18] S. Kasman, I.E. Saklakoglu, Kovove Mater. 51, 317-325 (2013).

[19] Ch. Yao, B. Xu, J. Huang, P. Zhang, Y. Wu, Optics and Lasers in Engineering 48, 20-26 (2009).

[20] A. Güral, Kovove Mater. 48, 25-31 (2010). 